\title{
Effect of lumbar sympathectomy on muscle blood flow: Distribution of perfusion measured by hydrogen clearance in skeletal muscle
}

\author{
BOK Y. LEE, M.D., F.A.C.S.; LEE E. OSTRANDER, Ph.D.; WILLIAM R. THODEN, M.A.; \\ JOHN L. MADDEN, M.D., F.A.C.S. \\ Departments of Surgery, Veterans Administration Medical Center, Castle Point, New York, New York Medical \\ College, Valhalla, New York, and Department of Biomedical Engineering, Rensselaer Polytechnic Institute, \\ Troy, New York
}

\begin{abstract}
Measurements of local tissue blood flow using a technique of hydrogen clearance were used to examine the effect of lumbar sympathectomy on skeletal muscle blood flow. Polarographic recordings on 25 hydrogen desaturations were obtained with platinized platinum electrodes. Lumbar sympathectomies were done on five canines leaving the contralateral limb as a control. The hydrogen clearance data were modeled with biexponential curves: the initial rapid component and the second slow component yielded a weighted average perfusion through tissue. Average volumetric blood flow in the control limb was $6.08 \pm 0.45 \mathrm{ml} / \mathrm{min} / 100 \mathrm{~g}$ tissue while the sympathectomized limb averaged $9.54 \pm 0.61 \mathrm{ml} / \mathrm{min} / 100 \mathrm{~g}$ tissue $(p<0.005)$. Average blood flow increases ranged from 33 to 83 percent in the sympathectomized limb over the control limb. This significant increase in muscle blood flow following lumbar sympathectomy, if of prolonged duration, may be cause for re-evaluation of the role of sympathectomy in the management of arteriosclerotic occlusive disease.
\end{abstract}

DOI $10.1682 / J R R D .1987 .07 .0001$

\section{INTRODUCTION}

The role of lumbar sympathectomy in the management of arteriosclerotic occlusive disease of the lower limb has been subject to longstanding controversy. The technique has regressed from a period of widespread use as the sole treatment available for obstructive arterial disease to its current status where it is infrequently used, if at all. The experience of the authors (11-17) has demonstrated beneficial effects from lumbar sympathectomy. In the presence of digital gangrene, Lee et al. (13) have found lumbar sympathectomy to be very beneficial in achieving limb and toe salvage.

Although the work of Lee et al. $(11,12,16)$ and Collins et al. (4) have shown lumbar sympathectomy to yield an increase in total limb blood flow, the presence of increased blood flow, and its benefit when present, have been debated $(5,6,10,21,22)$. The present study has been done to determine the effect of lumbar sympathectomy on muscle blood flow in the canine hind limb, using the technique of hydrogen clearance.

The use of hydrogen clearance as a technique for monitoring blood flow was first introduced by Aukland $(1,2)$. Hydrogen gas is highly suitable for use as a blood flow tracer as it has been shown $(1,2,7)$ to meet the most important criteria for a tracer substance as set forth by Ketz (9). It was shown to be metabolically inert, not normally found in tissue, readily soluble in lipids, it rapidly diffuses through tissues, and because of a low water-gas partition coefficient $(0.018)$ it is rapidly removed from the arterial circulation in its passage through the lungs. Young (24) points out that the use of hydrogen clearance is advantageous in that it can be monitored at any location where a small platinum electrode can be inserted, multiple flow determinations can be made over a prolonged period of time at the same site, and an estimate of blood flow can be made from the clearance rate of the gas independent of the absolute amplitude of the hydrogen signal. The only requirement is that the electrode response 
Journal of Rehabilitation Research and Development Vol. 24 No. 3 Summer 1987

remain linear and constant over the time course of the clearance. The instrumentation required is relatively inexpensive and simple to use, and supplies of hydrogen gas are readily available.

\section{MATERIALS AND METHODS}

\section{Experimental Procedures}

Data were collected from five healthy female canines (age range 2 to 7 years (mean \pm S.D.: 3.7 \pm 1.9 years). They ranged in weight from 11.3 to $15.9 \mathrm{~kg}$ (mean \pm S.D.: $13.6 \pm 5.3 \mathrm{~kg}$ ). Unilateral lumbar sympathectomies were done, leaving the contralateral non-sympathectomized limb to serve as a control. The elapsed time between sympathectomy and hydrogen clearance ranged from 1 to 13 months. The animals were anesthetized with halothane and mechanically ventilated during each study. The breathing gas was switched from a room-air/ halothane mixture to a room-air/halothane $/ 3$ percent hydrogen mixture to begin each study. A 20 to 30 minute period of ventilation with the 3 percent hydrogen mixture was required in order to obtain saturation of the tissues with hydrogen. Twentyfive hydrogen desaturations were carried out by a step change return to the room-air/halothane mixture. The number of desaturations on any single animal ranged between three and seven.

The clearance curves (the measured hydrogen concentration changes leading to desaturation) were recorded from the right and left gastrocnemius muscles simultaneously. Remote silver/silver-chloride electrodes served as references. The hydrogen monitoring probes were polarized to $+300 \mathrm{mv}$ (with respect to the reference electrodes) using Transidyne Chemical Microsensors, to maximize their specificity to hydrogen. The probes were inserted into new positions in the muscles prior to each hydrogen desaturation so that an average blood flow for the entire muscle could be calculated. After insertion, the probes were secured to both the animal and the surgical table. The polarographic signals from the right and left were simultaneously recorded on a strip chart. Each recording was continued for 15 to 25 minutes until the change in the response was less than 1 percent of the total response per minute, thereby indicating that desaturation was complete. The probe's sensitivity to hydrogen was verified both before and after each animal's experiments.

\section{Probe Construction}

The hydrogen-monitoring probes were constructed using Gross E2B subdermal platinum electrodes electroplated with a platinum black layer according to the methods of Aukland et al. (2). The electroplating of the probe increases its surface area, thus increasing its reactions with the tracer substance (hydrogen).

The initial step in constructing the probe is the insulation. The insulation lacquer used was clear Insl-X insulating-tool dip, diluted 1:3 with Insl-X thinner. The probes were dipped in the mixture and allowed to dry with tips upright to obtain a smooth insulating layer. (Approximately 3 to 5 layers are necessary for proper insulation, allowing at least 1 hour of drying time between layers.) The probes were inspected for sufficient resistance properties with an ohmmeter; a resistance of $10^{8}$ ohms or greater was considered acceptable. The beveled tip of the probe was then exposed by scraping off the insulation and sanding it with 400 grade sandpaper.

To electroplate the probe, a 1.5 -volt battery was connected in series with the probe. The circuit was completed by connecting a second non-insulated probe to the battery and then submerging both probe tips into a 5 percent platinum-chloride solution. To achieve a finely dispersed platinum deposit, the plating was continued for 10 minutes with a current of 25 microamperes $(\mathrm{mA})$ (measured by an ammeter connected in series with the probe). This electroplating scheme yields a light, gray shading that is barely visible on the tip of the probe. Successful plating was verified under a light microscope prior to each dog's use. The probes were stored in dry air at room temperature until use $(2,3)$. The probes were found to remain sensitive for approximately 1 to 2 weeks after electroplating, with a maximum stability obtained after 2 to 3 days.

\section{Data Analysis}

The recorded clearance curves were manually digitized and subsequently analyzed using a curvefitting computer program (P3R BMDP Biomedical Computing Program).

The curves obtained in this study were best described by a biexponential model making it possible to consider the hydrogen clearance curves as a sum of two exponential terms:

$$
\left[\mathrm{H}_{2}\right]=\mathrm{Ae}^{-\mathrm{k}_{1 \mathrm{t}}}+\mathrm{Be}^{-\mathrm{k}_{2 \mathrm{t}}}
$$

where $A$ and $B$ represent the intercepts of the 
exponentials and $\mathrm{k}_{1}$ and $\mathrm{k}_{2}$ represent the clearance of the individual compartments. The average flow rate $(\overline{\mathrm{Q}})$ was calculated using the following equations $(18,23)$ :

$$
\bar{t}_{1 / 2}=\frac{(\mathrm{Yo})_{\mathrm{A}}\left(\mathrm{t}_{1 / 2}\right)_{\mathrm{A}}+(\mathrm{Yo})_{\mathrm{B}}\left(\mathrm{t}_{1 / 2}\right)_{\mathrm{B}}}{(\mathrm{Yo})_{\mathrm{A}}+(\mathrm{Yo})_{\mathrm{B}}} \text { (sec.) }
$$

where

$(\mathrm{Yo})_{\mathrm{A}}=$ the $y$-intercept of the slow component

$(\mathrm{Yo})_{\mathrm{B}}=$ the $y$-intercept of the fast component

$\left(t_{1}\right)_{A}=$ the half-time of the slow component

$\left(t_{\frac{1}{2}}\right)_{B}=$ the half-time of the fast component.

$$
\begin{gathered}
\bar{\tau}=\frac{\overline{\mathrm{t}}_{1 / 2}}{0.693}(\mathrm{sec} .) \\
\overline{\mathrm{Q}}=\frac{5714}{\bar{\tau}}(\mathrm{ml} / \mathrm{min} / 100 \mathrm{~g} \text { tissue })
\end{gathered}
$$

A slow flow component was also calculated by substituting $\left(\bar{t}_{\frac{1}{2}}\right)_{A}$ for $t_{\frac{1}{2}}$ in equations [2] and [3], which in case $\bar{Q}$ is replaced by $Q_{A}$. A fast flow component was similarly calculated using $\left(\mathrm{t}_{2}\right)_{B}$ to obtain $\mathrm{Q}_{B}$.

A simplified calculation method for overall flow using half-response time also was employed for comparison purposes. This method assumes that the clearance curve may be modeled with a single exponential, and identifies a half-response time as the time when the hydrogen concentration is at onehalf its maximum value. The half-response time is then substituted for $\bar{t}_{\frac{1}{2}}$ in equations [2] and [3] to obtain a simplified perfusion estimate, $\overline{\mathrm{Q}}_{50}$. This second method is much simpler to implement but does not provide any information regarding the distribution of perfusion in the muscle. Nevertheless, it useful as a comparative method.

Data are presented as mean \pm standard deviation.

\section{RESULTS}

\section{Mean Perfusion}

It was necessary to discard 3 of the 25 pairs of desaturation data. In one animal the monitoring electrode in the left limb slipped out of the muscle and was not recording skeletal muscle perfusion. In the second case, the animal began to come out of anesthesia and muscle tremors rendered the recordings useless. In another animal the response of the right limb was approximately linear and did not fit the biexponential curve-fitting criterion. However, the desaturation data were analyzed using the halfresponse time method and a reasonable perfusion rate was obtained.

Assuming a biexponential model, the average blood flow $(\overline{\mathrm{Q}})$ in the control limb of the 23 acceptable desaturations was $6.08 \pm 0.46 \mathrm{ml} / \mathrm{min} / 100 \mathrm{~g}$ tissue in the control limb and $9.54 \pm 0.61 \mathrm{ml} / \mathrm{min} / 100 \mathrm{~g}$ tissue in the sympathectomized limb. Analysis for pairwise differences showed this difference to be statistically significantly different $(p<0.005)$. (The 95 percent confidence interval for the difference in perfusion between limbs was 2.03 to $5.03 \mathrm{ml} / \mathrm{min} /$ $100 \mathrm{~g}$ tissues.) The average flow in the sympathectomized limb was 33 to 83 percent greater than in the control limb. The apparent difference demonstrated that sympathectomy has a definite effect on the distribution of flow in skeletal muscle.

Four distinct flow values were determined: $\overline{\mathrm{Q}}_{50}$, which is the average blood flow determined from the time constant of a single exponential; $\mathrm{Q}_{\mathrm{B}}$, which is the fast flow component; $Q_{A}$, the slow flow component; and $\overline{\mathrm{Q}}$, the average weighted blood flow calculated from the fast and slow flow components. The overall flow $(\bar{Q})$ is a weighted sum of the flow components $\mathrm{Q}_{\mathrm{A}}$ and $\mathrm{Q}_{\mathrm{B}}$. The weighting factors, $\left(\mathrm{Yo}_{\mathrm{A}}\right.$ and $(\mathrm{Yo})_{\mathrm{B}}$ (Table 1), determine the contributions of each compartment to $(\overline{\mathrm{Q}})$. For the right limb, $\left(\mathrm{Yo}_{\mathrm{A}}\right.$ averaged $.40 \pm 0.46$ percent of the total desaturation response, and $(\mathrm{Yo})_{B}$ averaged $0.61 \pm 0.47$ percent. In the left limb, the slow component had a greater contribution with $(\mathrm{Yo})_{\mathrm{A}}$ averaging $0.75 \pm 0.34$ percent while $(\mathrm{Yo})_{\mathrm{B}}$ averaged $0.26 \pm 0.34$ percent.

\section{Table 1}

Fast and slow flow component weighting factors (average percent of the total desaturation response)

\begin{tabular}{lcc}
\hline & Sympathectomized & Control \\
\hline $\begin{array}{l}\text { Slow Flow } \\
\left(\mathrm{Y}_{0}\right) \mathrm{A}\end{array}$ & $37.7 \pm 9.2$ & $42.4 \pm 8.3$ \\
$\begin{array}{l}\text { Fast Flow } \\
\left(\mathrm{Y}_{0}\right) \mathrm{B}\end{array}$ & $29.5 \pm 10.2$ & $34.9 \pm 10.5$ \\
\hline
\end{tabular}

Mean \pm S.D.

Flow values for right and left limbs are shown in Figure 1. The slow flow components are essentially the same in the control and sympathectomized limb. 


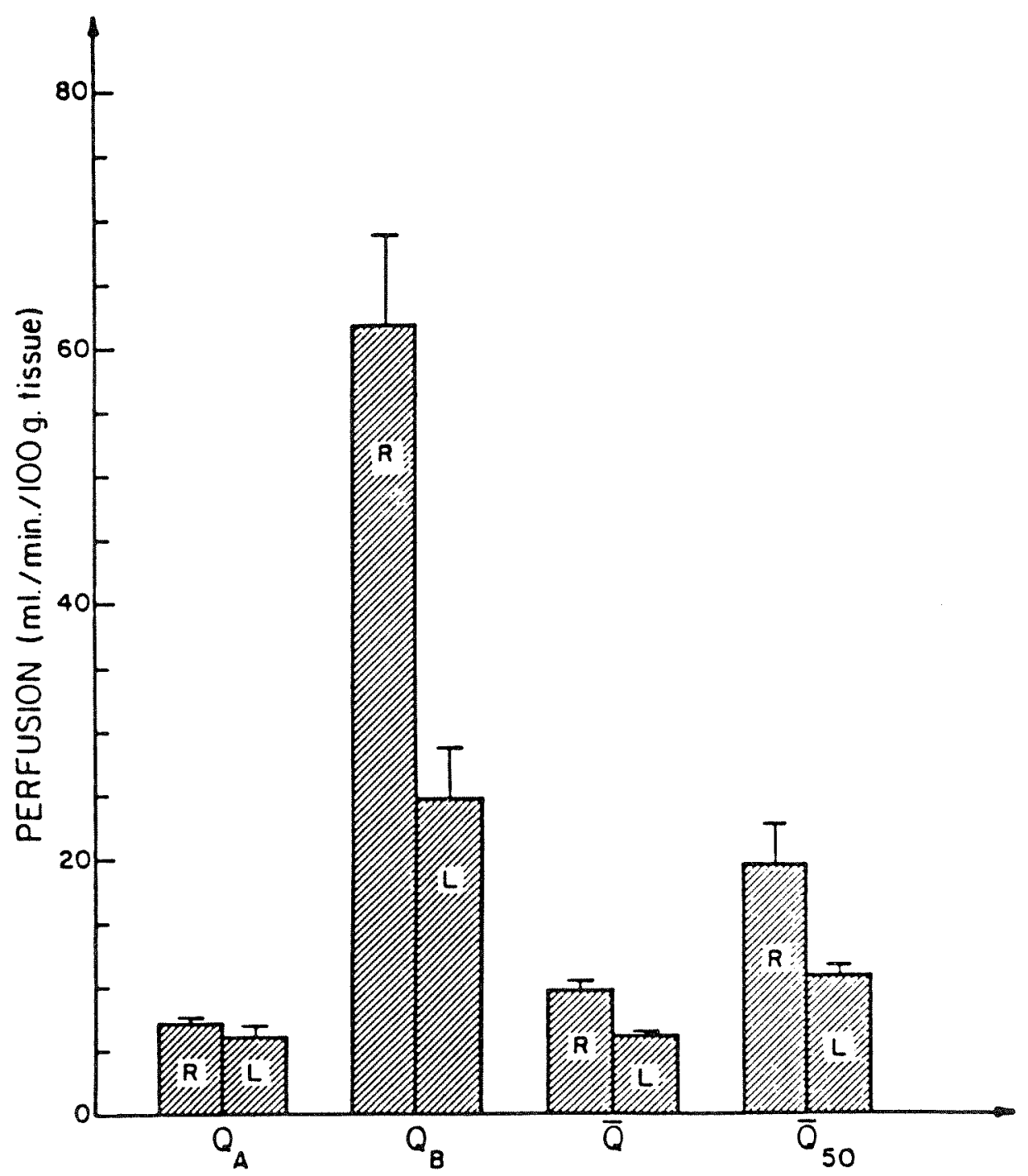

Figure 1.

Flow values for sympathectomized $(R)$ and control $(L)$ limbs. $Q_{A}=$ slow flow component;

$\mathrm{Q}_{\mathrm{B}}=$ fast flow component; $\overline{\mathrm{Q}}=$ average weighted blood flow; $\overline{\mathrm{Q}}_{50}=$ average blood flow.

The greatest flow change is seen in the fast flow component and accounts for the significant difference in $(\bar{Q})$. The perfusion rates calculated from half-response times are consistently higher than those for the exponential methods, although similar differences between the two limbs may be seen. This effect may be explained by noting that the $\mathrm{Q}_{50}$ values estimate a biexponential curve with a monoexponential model, thereby introducing substantial error. As the biexponential regression method provides a more detailed breakdown of the distribution of perfusion and assumes a model more closely matching the data, we consider it the analysis method of choice.

\section{Flow Rate Distributions}

A more detailed representation of the flow rate distribution differences between control and sympathectomized limbs is presented in Figures 2-5. As shown in Figure 2, the median value of $Q_{A}$ (i.e., the 50 percent point) is approximately the same for both limbs. Additionally, the two curves differ in that the sympathectomized limb shows fewer data with very low flows when compared with the control limb.

The distribution plot for the fast flow component $\left(Q_{B}\right.$, in Figure 3) shows some extremely high flow rates beyond the range of the distribution plot (107.1, $128.2,165.9$, and $195.8 \mathrm{ml} / \mathrm{min} / 100 \mathrm{~g}$ tissue). At the median value of $\mathrm{Q}_{B}$, the sympathectomized limb 


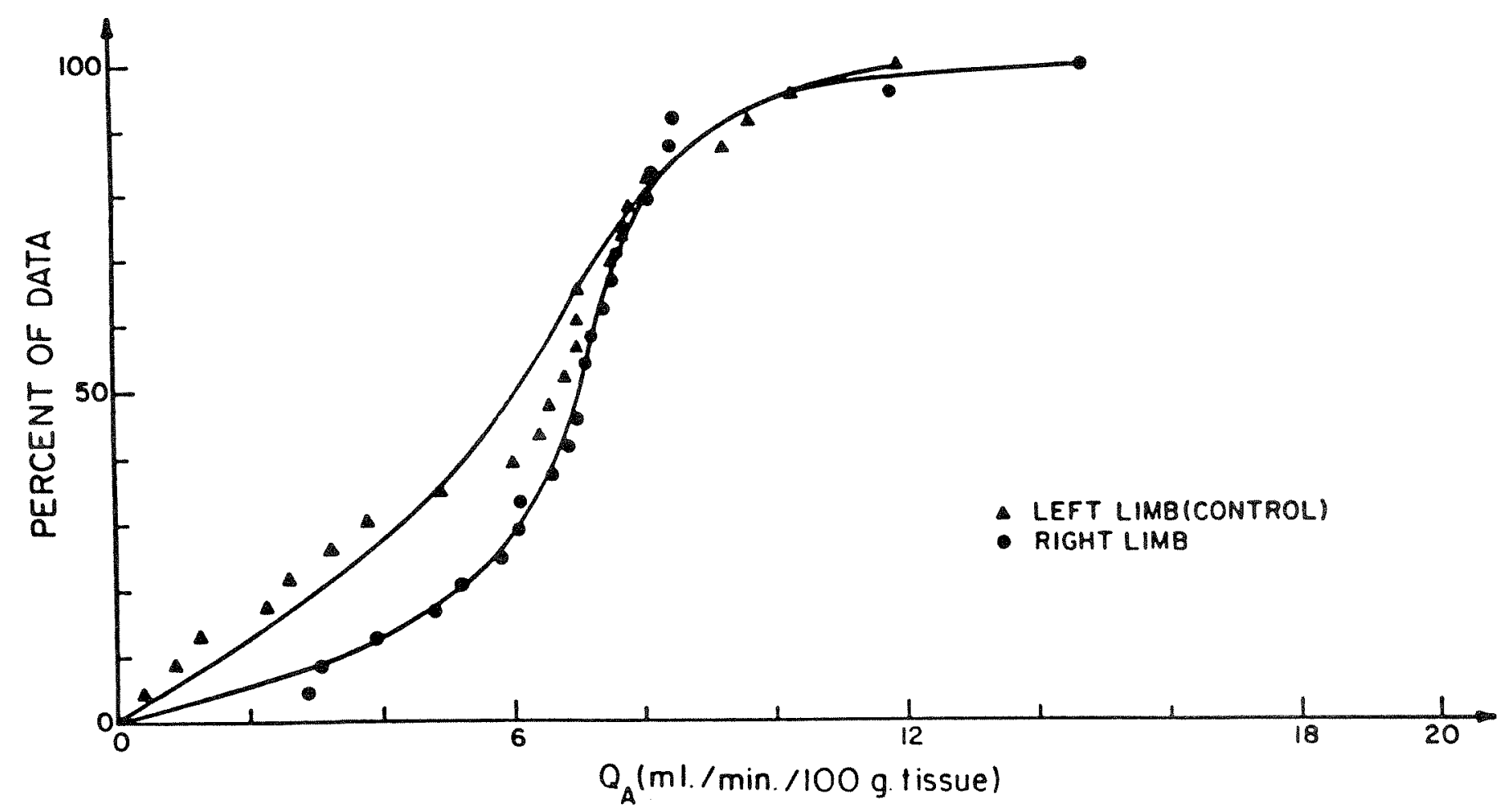

Figure 2.

Distribution plot for perfusion data for slow flow component $\left(Q_{A}\right)$.

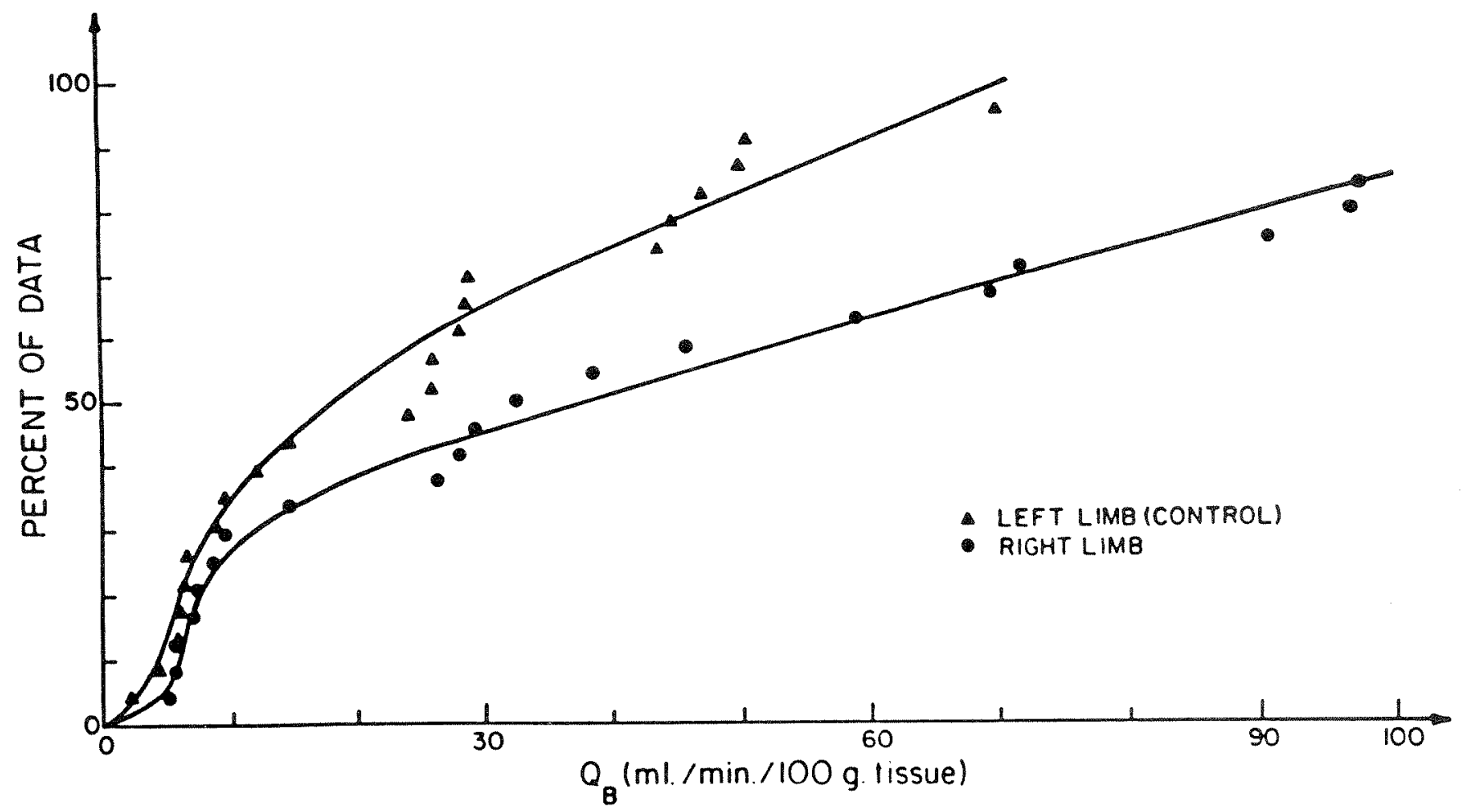

Figure 3.

Distribution plot for perfusion data for fast flow component $\left(Q_{B}\right)$. 


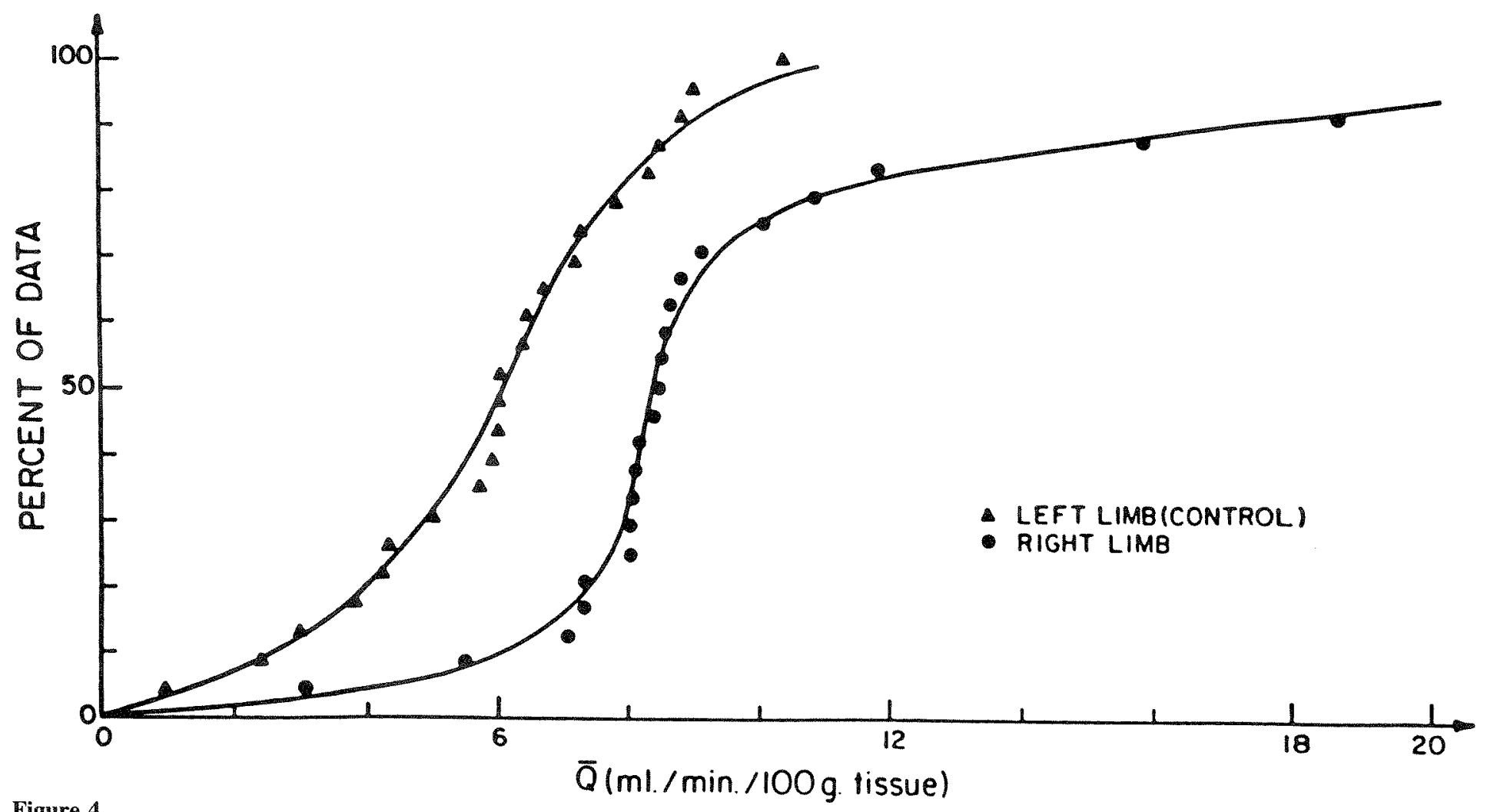

Figure 4.

Distribution plot for weighted average blood flow $(\overline{\mathrm{Q}})$ combining data from Figures 2 and 3.

flow is much greater than the control limb. Thus, in both fast and slow components, the sympathectomized limb shows a decrease in the number of extremely low flows and an increase in the number of extremely high flows.

Figure 4 is derived from a combination of data from Figures 2 and 3 to give a weighted average blood flow, $(\bar{Q})$. It illustrates a significant difference between the sympathectomized and control limb at the median point, and there is evidence of an increased number of fast flows at the upper end of the curve and a decreased number of slow flows at the lower end for the sympathectomized limb. Similar effects are seen for the data for $\overline{\mathrm{Q}}_{50}$ based on the half-time analysis (Figure 5).

\section{DISCUSSION}

The results of this analysis of hydrogen clearance curves between sympathectomized and control limbs show distinct overall perfusion differences: an increase in the number of extremely high flows and a decrease in the number of very low flows for the sympathectomized limb. The distribution of regional perfusion in skeletal muscle obtained via a biexponential regression method provides additional insight into the differences in the overall flow and blood flow components, following lumbar sympathectomy. The results indicate the greatest flow change to occur in the fast flow components, accounting for the significant differences in the overall flow $(\bar{Q})$ following sympathectomy. It is interesting to note that the hydrogen clearance curves from sympathectomized and control limbs were recorded simultaneously, allowing pairwise perfusion differences to be examined for one desaturation in a single animal.

In the past, biexponential clearance curves have been explained by assuming the presence of an arteriovenous shunt. However, since the biexoponential clearance curves recorded in this study were observed while monitoring skeletal muscle tissue, a true arteriovenous shunt could not explain their existence. It would most logically appear that a heterogeneous flow is present in the tissue. Although a theory of distinct, anatomical compartments with different flows could explain the curves, anatomical observation of skeletal muscle does not support such a model. Another type of heterogeneous flow 


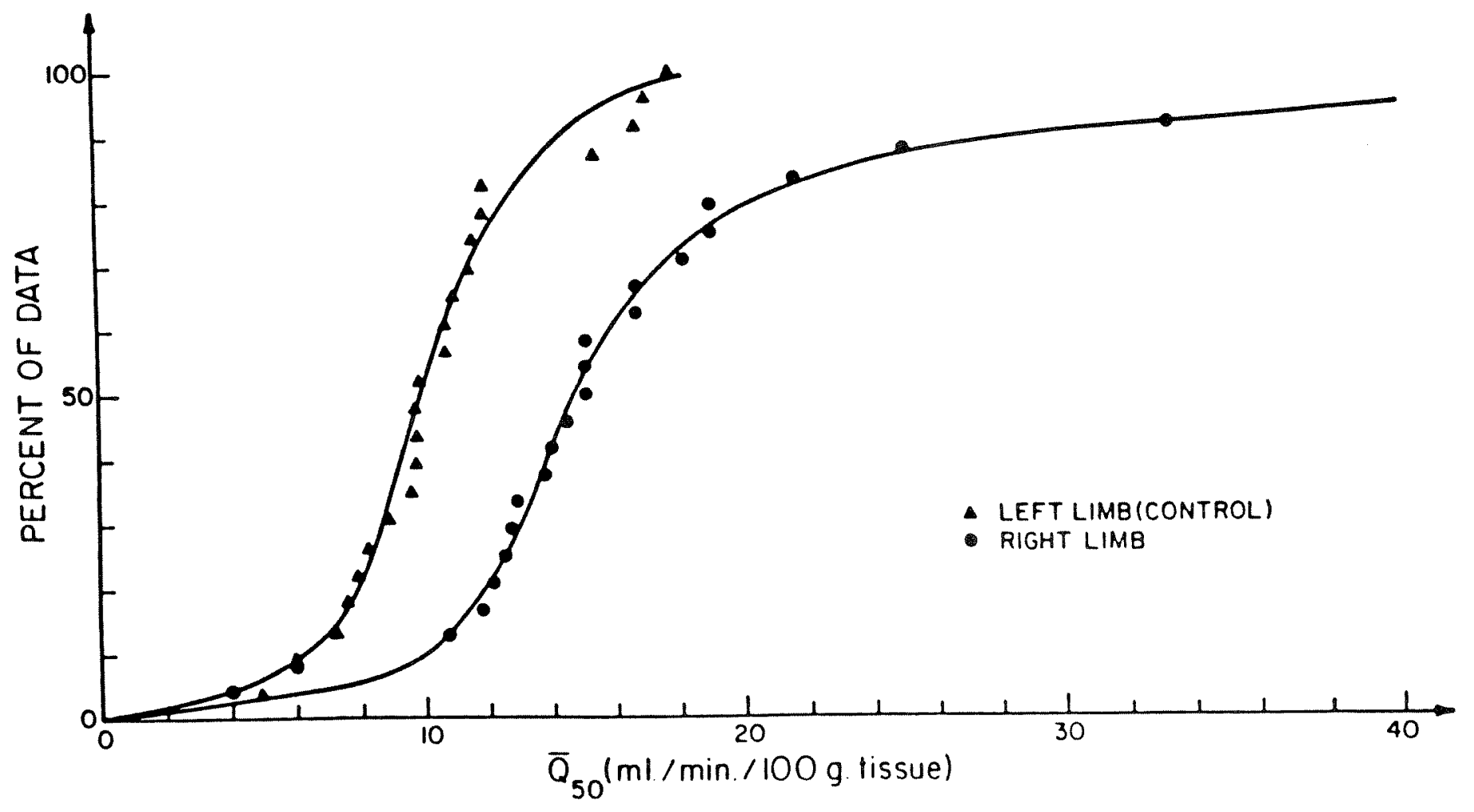

Figure 5.

Distribution for average blood flow $\left(\overline{\mathrm{Q}}_{50}\right)$.

could be created by a "physiological shunt," as described by Renkin and Rosell (20); a short capillary with very high flow. Such a vessel could only supply nutrients to a relatively small volume of tissue as compared with a long capillary with very low flow. The physiological implication is that a considerable volume of blood is in contact with a relatively small volume of tissue for a very short period of time. Although the results of the present study are insufficient to make absolute conclusions regarding skeletal muscle blood flow or the effect of lumbar sympathectomy, there does seem to be an increase in the fast flow component of skeletal muscle perfusion following sympathectomy, indicating the possible existence of an increased "physiological shunt."

Clinically, the effect of lumbar sympathectomy on blood flow to the lower extremities has been the subject of conflicting reports. Assuredly, lumbar sympathectomy results in the loss of vascular tone in vessels, supplied by vasoconstrictor fibers, and there is a general consensus that skin capillary blood flow is augmented following lumbar sympathectomy. Moore and Hall (19), using a xenon clearance technique, have estimated a three-fold increase in nutritional blood flow to the pretibial skin. The success in the management of digital gangrene as reported by Lee et al. (13) is most probably a result of the increased nutritive skin blood flow.

There also is clinical evidence that lumbar sympathectomy increases total limb blood flow, although a general consensus is lacking. Reports by Lee et al. $(11,12)$ and Collins et al. (4) showing increases in limb blood flow are opposed by reports showing no augmentation (e.g., 6,8). The results of the present study, however, have indeed shown increased skeletal muscle blood flow to the lower extremity following sympathectomy.

These results apply for iliac artery ligation. A dependence on the location of the arterial obstruction could account for the reported differences among investigators in the benefits of sympathectomy. With good arterial supply, the possibility of increased fast flow components within limb tissues becomes possible, as seen in this study. For example, in our earlier work when sympathectomy was found to be beneficial, a Doppler above-knee/ brachial pressure index of 0.6 or better served as a criterion to indicate adequate inflow to the popliteal level. For patients above the 0.6 level, a good response was obtained from lumbar sympathectomy 
Journal of Rehabilitation Research and Development Vol. 24 No. 3 Summer 1987

in 78 percent of 101 consecutive cases.

The duration of the increased flow from sympathectomy also has been a matter of controversy but is not, in fact, a big issue. Of primary importance is the creation of conditions which accomplish healing. In the present study, we have seen an increase in muscle flow during measurements several months postsympathectomy. This suggests that the role of sympathectomy is to promote healing through increased flow in the presence of limited areas of pregangrene or actual gangrene of the toes without extensive involvement of the foot. Once healing has occurred in the clinical situation, preservation of the limb is reflected in an increased rate of limb salvage. For example, we have reported a retrospective review of 45 patients with toe gangrene, not amenable to direct arterial surgery and managed with lumbar sympathectomy (13). We found an 8 year cumulative limb salvage rate of 71 percent, with a 51 percent cumulative toe salvage rate.

The combination of noninvasive vascular assessment and good clinical judgment may well lead to selective use of lumbar sympathectomy in the management of symptomatic arteriosclerotic occlusive disease when it is of the severity to require surgical procedure and where arterial reconstruction is not feasible because of diffuse distribution of disease and poor distal runoff.

\section{REFERENCES}

1. AUKLAND K: Hydrogen polarography in measurement of local blood flow, theoretical and empirical basis. Acta Neurol Scand 41(suppl. 14):42-45, 1965.

2. AuKLAND K, Bower BF, Berliner RW: Measurement of local blood flow with hydrogen gas. Circ Res 14:164$187,1964$.

3. Aukland K, Kill F, Kuekshus J, Semt G: Local myocardial blood flow measured by hydrogen polarography: Distribution and effect of hypoxia. Acute Physiol Scand 70:99-111, 1967.

4. Collins GJ, Rich NM, Andersen CA, et al.: Acute hemodynamic effects of lumbar sympathectomy. Am J Surg 136:714-718, 1978.

5. CRonenwalt JL And Lindenauer M: Direct measurement of arteriovenous blood flow after lumbar sympathectomy. Surgery 82:82-89, 1977.

6. FOLSE R, MARK RM, CANTRELl JR: Alterations in femoral blood flow and resistance following sympathetic blockage: Hemodynamic evaluation of patients with and without arterial occlusion by dye technique. Ann Surg 162:873$880,1965$.

7. GoToh F, MEYeR JS, Tomita M: Hydrogen method for determining cerebral blood flow in man. Arch Neurol 15:549-559, 1966.

8. HofFMAN DC AND JEPSON RP: Muscle blood flow and sympathectomy. Surg Gynecol Obstet 127:12-16, 1968.

9. KETZ SS: The theory and applications of the exchange of inert gas at the lungs and tissue. Pharmacal Rev 3:1-41, 1951.

10. Lassen NA, Larsen DA, Sorenson AWS, et al.: Conservative treatment of gangrene using minimal corticoidinduced moderate hypertension. Lancet 1:606-609, 1968.

11. LEE BY, MADDEN JL, MCDONough WB: Use of squarewave electromagnetic flowmeter during direct arterial surgery, before and after lumbar sympathectomy in peripheral vascular surgery. Vasc Surg 3:218-242, 1969.

12. LEE BY, LAPoINTE DG, MADDEN JL: Evaluation of lumbar sympathectomy by quantification of arterial pulsatile waveform. Vasc Surg 5:61-87, 1971.
13. Lee BY, Madden JL, Thoden WR, MCCANN WJ: Lumbar sympathectomy for toe gangrene: Long-term followup. Am J Surg 145:398-401, 1983.

14. LEE BY AND THODEN WR: The role of sympathectomy in peripheral vascular disease. In: Goldsmith HS (ed.) Practice of Surgery, Chapter 14. Hagerstown: Harper and Row, 1981.

15. LeE BY, Thoden WR, Kavner D, Trainor FS: Predicting the effects of surgical sympathectomy by noninvasive vascular assessment. Contemp Surg 18:79-82, 1981.

16. LeE BY, Thoden WR, MAdDen JL, et al.: Long-term followup of bypass procedures with and without sympathectomy. Contemp Surg 20:51-55, 1982.

17. LEE BY, Trainor FS, KaVNer D, et al.: Management of severe foot ischemia secondary to occlusive vascular disease. Surg Gynecol Obstet 148;305-309, 1979.

18. MCFARLAND WJ, Condos SG, Geba AS: Telemetry of regional tissue blood flow using hydrogen clearance. Proc 8th New Eng Bioeng Conf, pp 40-43, 1980.

19. MoORE WS AND HALL AD: Effects of lumbar sympathectomy on skin capillary blood flow in arterial occlusive disease. I Surg Res 14:151-157, 1973.

20. RENKIN EM AND ROSELL S: The influence of sympathetic adrenergic vasoconstrictor veins on transport of diffusible solutes from blood to tissue in skeletal muscle. Acta Physiol Scand 54:223, 1962.

21. RUTHERFORD RB AND VALENTA J: Extremity blood flow and distribution: The effects of arterial occlusion, sympathectomy, and exercise. Surgery 69:332-344, 1971.

22. VAN DE Berg L, DeWeese JA, RoB CG: The effect of arterial stenosis on blood flow and the ergogram. Ann Surg 159:623-635, 1964.

23. VAN LIEW HD: Graphic analysis of aggregates of linear and exponential processes. $J$ Theoret Biol 16:43-53, 1967.

24. YounG W: $\mathrm{H}_{2}$ clearance measurement of blood flow: $\mathrm{A}$ review of technique and polarographic principles. Stroke 11:552-564, 1980. 